\title{
Training in pediatric airway endoscopy during a pandemic and beyond
}

\author{
Albin Leong ${ }^{1}$, Dan Benscoter ${ }^{2}$, John Brewington $^{2}$, Cherie Torres-Silva $^{2}$, and Robert Wood $^{2}$ \\ ${ }^{1}$ UC Davis Children's Hospital \\ ${ }^{2}$ Cincinnati Children's Hospital Medical Center
}

December 29, 2020

\begin{abstract}
The pandemic has had a dramatic and negative impact on opportunities for training in pediatric airway endoscopy. This commentary discusses ways in which training programs can address this issue.
\end{abstract}

\section{Hosted file}

Commentary - training in pediatric airway endoscopy during a pandemic.pdf available at https://authorea.com/users/386001/articles/501268-training-in-pediatric-airwayendoscopy-during-a-pandemic-and-beyond 